wWw.volsu.ru

DOI: https://doi.org/10.15688/jvolsu3.2017.2.2

UDC 330

LBC 65

\title{
THE SYNERGETIC EFFECT OF THE SOCIO-ECONOMIC SYSTEM AS THE QUALITY OF INTERACTION OF ITS CONSTITUENT POTENTIALS
}

\author{
Isa M. Betilgiriev \\ Grozny State Oil Technical University named after M.D. Millionshchikov, \\ Grozny, Chechen Republic, Russian Federation \\ Maula A. Betilgiriev \\ Grozny State Oil Technical University named after M.D. Millionshchikov, \\ Grozny, Chechen Republic, Russian Federation \\ Khasan E. Taimaskhanov \\ Grozny State Oil Technical University named after M.D. Millionshchikov, \\ Grozny, Chechen Republic, Russian Federation
}

\begin{abstract}
The article analyzes the socio-economic system (SES) of the production orientation as a dynamic, probabilistic, open, self-organizing, self-regulating and multi-parameter system from the standpoint of using it as an important element of the organizational and economic mechanism for managing regions and the national economy as a whole, which requires the development of theoretical search for strengthening its integrative properties.

In the course of studying possible ways of integration in SES and subsequent processes of formation of synergistic potentials, it is noted that these processes are based on the establishment of rational (optimal) connectivity between the structures and functions of SES. Obviously, if the connectivity in the system is zero, then there is no interaction between its elements or subsystems, integration is excluded, and there is no positive synergetic effect, or, most likely, it is negative.

Due to the non-additivity of the properties of the elements of the SES system, it is studied as an integrated - formation based on the analysis of the connectivity of its constituent elements -potentials (production, 궁 organizational, innovation, infrastructure, personnel, financial, information, consumer, status), and each component $\therefore$ of the potential is subject to the action of not only general, but also their own specific laws and trends of development and has its own specific essence.

o It is established that this connectivity, determined on the basis of expert assessments, forms a matrix in which each element reflects a possible partial synergetic effect, and the entire matrix as a whole reflects the integral synergetic effect arising in the SES, which has some optimal value. The growth of the synergetic effect is directly related to the creative professional activity of SES specialists.
\end{abstract}

Key words: synergetic effect, potential, socio-economic system, organizational and economic mechanism.

УДК 330

ББК 65

\section{СИНЕРГЕТИЧЕСКИЙ ЭФФЕКТ СОЦИАЛЬНО-ЭКОНОМИЧЕСКОЙ СИСТЕМЫ КАК КАЧЕСТВО ВЗАИМОДЕЙСТВИЯ СОСТАВЛЯЮЩИХ ЕЕ ПОТЕНЦИАЛОВ}

\section{Иса Маулаевич Бетилгириев}

Грозненский государственный нефтяной технический университет им. академика М.Д. Миллионщикова, г. Грозный, Чеченская Республика, Российская Федерация 


\section{Маула Абдурахманович Бетилгириев}

Грозненский государственный нефтяной технический университет им. академика М.Д. Миллионщикова, г. Грозный, Чеченская Республика, Российская Федерация

\section{Хасан Элимсултанович Таймасханов}

Грозненский государственный нефтяной технический университет им. академика М.Д. Миллионщикова, г. Грозный, Чеченская Республика, Российская Федерация

Аннотация. В статье проводится анализ социально-экономической системы (СЭС) производственной направленности как динамической, вероятностной, открытой, самоорганизующейся, саморегулируемой и многопараметрической системы с позиций использования его как важнейшего элемента организационноэкономического механизма управления регионами и народным хозяйством в целом, что требует развития теоретических поисков усиления его интегративных свойств.

В работе в ходе изучения возможных путей интеграции в СЭС и последующих процессов формирования синергетических потенциалов отмечается, что эти процессы основываются на установлении рациональной (оптимальной) связности между структурами и функциями СЭС. Очевидно, что если связность в системе равна нулю, то и взаимодействий между ее элементами или подсистемами не существует, интеграция исключена, и положительный синергетический эффект отсутствует, или, вероятнее всего, он отрицателен.

В силу неаддитивности свойств элементов системы СЭС, она исследуется как интегрированное образование на основе анализа связности составляющих его элементов (потенциалов: производственный, организационный, инновационный, инфраструктурный, кадровый, финансовый, информационный, потребительский, статусный), причем каждая составляющая потенциала подчиняется действию не только общих, но и своих собственных специфических законов, закономерностей и тенденций развития и имеет свою специфическую сущность.

Установлено, что эта связность, определяемая на основе экспертных оценок, образует матрицу, в которой каждый элемент отражает возможный частичный синергетический эффект, а вся матрица в целом отражает возникающий в СЭС интегральный синергетический эффект, имеющий некоторое оптимальное значение. Рост синергетического эффекта непосредственно связан с созидательной профессиональной деятельностью специалистов СЭС.

Ключевые слова: синергетический эффект, потенциал, социально-экономическая система, организационно-экономический механизм.

Чтобы социально-экономическая система (СЭС) действовала эффективно и создавала возможности для народнохозяйственного развития, нужно ориентироваться на одновременное удовлетворение требований и к ее функционированию, и к развитию. Необходимо обеспечивать постоянную связь между настоящим и будущим, учитывать возможности и возникающие риски внешней и внутренней природы, новые факторы производства, обращения и потребления, рыночной инфраструктуры, а также законы и новые тенденции развития воспроизводственных процессов как в обществе, так и в природе.

Рассматривая сложную динамическую, вероятностную, открытую и многопараметрическую систему, важно обратить особое внимание на необходимость научно-методических поисков усиления ее интегративных свойств, призванных обеспечить направления и методы повышения эффективности СЭС с использованием позитивных синергетических эффектов различной природы.

Напомним кратко, что синергетические эффекты в СЭС возникают как в интегрированных самоорганизующихся системах с нелинейными связями и существенным влиянием процессов и факторов вероятностной природы. Они проявляются в социально-экономических системах различной природы и различных масштабов [9].

Как отмечено в работе [10], в макромасштабе потенциалом синергии в нашей стране обладает системная интеграция научного, промышленного и финансового капитала на различных уровнях. Однако в настоящее время между ними существует разрыв, изолированность, по существу, пропасть. К сожалению, пока в России не сформированы организационно-экономические механизмы интеграции этих сфер, без которых не могут быть обеспечены как масштабные, так и локальные си- 
нергетические процессы, являющиеся локомотивом социально-экономического, материального и духовного развития [11]. В формировании синергетических эффектов важную роль играют вертикальные и горизонтальные связи и взаимодействия между субъектами хозяйственной деятельности на всех уровнях СЭС. В качестве инструментов интеграции выступают миссия, система согласованных целей, задач, принципов, совпадение (сходство) институциональных форм, методов, инструментов и рычагов управления [10].

Рассматривая возможные пути интеграции в СЭС и последующих процессов формирования синергетических потенциалов, необходимо отметить, что эти процессы основываются на установлении рациональной (оптимальной) связности между структурами и функциями СЭС. Очевидно, что если связность в системе равна нулю, то и взаимодействий между ее элементами или подсистемами не существует, интеграция исключена, и положительный синергетический эффект отсутствует, или, вероятнее всего, он отрицателен. Если связность максимальна (условно равна единице), то связанные элементы или подсистемы субъекта хозяйствования теряют необходимую свободу своей активности, и функции синергичности системы также приобретают явно отрицательный характер [18].

Таким образом, эффект интеграции (и, как следствие, эффект возможной синергии) в системе является функцией, по крайней мере, трех факторов:

1) уровня функционального и структурного развития каждого из взаимодействующих элементов или подсистем СЭС;

2) уровня связности между элементами или подсистемами;

3) свойств многофакторной взаимоадаптивности элементов.

При этом отметим, что оценки уровня функционального развития указанных факторов предполагают определенные количественные характеристики, включающие, например, профессиональную компетентность кадров, особенно руководителей и специалистов, качество коммуникаций, уровни организации производственных процессов, имидж организации и т. д.

Оценка уровня связности элементов или подсистем субъектов хозяйствования предпо- лагает не только наличие самих связей, но и их количественную оценку (вероятнее всего, экспертную) в определенных (условных) единицах.

В экономико-организационных системах можно отметить следующие типы функциональных связей: а) экономические; б) информационные; в) организационные; г) технологические; д) производственные; е) психологические; ж) кадровые; з) профессиональные и т. д.

Наряду с этим имеется и другой тип связей - между объектами (подсистемами) СЭС, который в определенной степени интегрирует различные функциональные связи и характеризуется различным уровнем связности самих структурных образований (потенциалов) СЭС.

Для оценки уровня развития СЭС более подробно остановимся на возможностях методического подхода, используемого в работе [14]. Автор указанного исследования характеризирует СЭС как комбинацию всех факторов, участвующих в производстве конечного продукта, включающую частные потенциалы: производственный; организационный; инновационный; инфраструктурный; кадровый; финансовый; информационный; потребительский; статусный; потенциал нормативно-правовых актов федеральной, региональной власти и органов местного самоуправления.

Принимая данный подход как приемлемый для целей нашего исследования, рассмотрим предлагаемые частные потенциалы СЭС подробнее, внеся ряд необходимых дополнений и уточнений.

1. Производственный потенциил. На наш взгляд, он должен включать не только производственный потенциал самой СЭС, но и все те мощности (не только в масштабах республики, но и государства), которые могут, по мере надобности, быть включены в деятельность СЭС (научные разработки, технологии, уникальное подъемно-транспортное оборудование, системы логистики и т. д.).

2. Организационный потенциал. Для того чтобы дать определение этой компоненте потенциала, нужно, прежде всего, исходить из логической трактовки самой функции организации, одной из самых сложных функций управления. Организация направлена на обоснование и выбор элементов системы управления и управляемой системы и на установление между ними пространственно-временных 
и причинно-следственных связей. Именно организационный потенциал в наибольшей степени способствует синтезу потенциала СЭС в единую интегрированную систему. Из управляющей и управляемой системы могут постепенно, поэтапно исключаться определенные устаревшие элементы, но включаться новые, которые будут выполнять и новые интегрирующие функции. В управляющей и управляемой системах происходят процессы установления новых и устранения устаревших пространственно-временных и причинно-следственных связей. Для согласования деятельности элементов СЭС, находящихся в разных точках региона и страны, необходимо установление пространственно-временных связей с учетом внутренних и внешних условий. В состав организационного потенциала, несомненно, следует включать систему нормативно-правовых актов международного, федерального, регионального и местного уровней (законодательная, исполнительная и судебная власть).

3. Инновационный потенииал представляет собой, по мнению автора, сложное структурное многофакторное образование, поскольку в качестве инноваций следует рассматривать новые предлагаемые элементы всей организационно-технологической и социально-экономической цепочки решений - от исследовательских и проектных работ и кончая технологиями эксплуатации уже созданных СЭС продуктов, а также новые экономические подходы и методы [17]. Иными словами, инновационный потенциал следует рассматривать на всех стадиях жизненного цикла производственных процессов и создаваемой СЭС продукции, где наибольшую ценность представляют самые ранние интеллектуальные стадии исследований, проектирования и разработок. Именно здесь сосредоточены основные резервы сокращения материальных, трудовых и финансовых затрат: инновации все больше переносятся в сферу идей, что позволяет впоследствии получить мощный синергетический эффект [15]. Отметим важный аспект инноваций - практически все подсистемы потенциалов и их взаимодействие могут продуцировать инновации. Так, несомненны возможности генерации инноваций в сферах производственного, потребительского, инфра- структурного, кадрового, информационного потенциалов. Особыми могут быть инновации в сферах организационного и инвестиционного потенциалов, которые также интегрируются в инновационном потенциале; классические примеры - саморегулируемые организации (СРО) и ассоциации, новые нормативно-правовые акты в сфере деятельности СЭС и т. д. [3; 4].

4. Инфраструктурный потенциал. Включает все элементы, которые необходимы для обеспечения функционирования СЭС: системы удовлетворения различных общественных потребностей - жилищно-бытовая сфера, рекреации, потенциал транспортно-логистических сетей, телекоммуникаций и т. д.

5. Кадровый потенииал. Это, прежде всего, носитель профессионального, творческого интеллекта. Любой потенциал СЭС - это производное, следствие активности кадрового потенциала; инновации, инвестиции, эффективность их привлечения и использования и т. д., обусловлены деятельностью персонала СЭС. Задача развития кадрового потенциала - формирование определенной структуры и содержания профессиональных качеств работников массовых профессий, специалистов, которые владеют совершенными методами технологий не только производства, но и научной, и организационной деятельности, финансовой, экономической, воспитательной работы и т. д. [19].

В системе кадрового потенциала огромную роль играет формирование морально-этических установок, воли, решимости, нацеленности, перспективности, то есть видение будущего с позиции морально-этической ответственности в преемственности поколений.

6. Инвестиционный (финансовый) потенциал. Потенциал развития СЭС в стоимостном выражении можно представить, используя уточненное содержание формулы [13]:

$$
P=\sum_{i=1}^{I} \Phi \mathrm{P}_{i}+\sum_{n-1}^{N} C_{n}+\sum_{k=1}^{K} A_{k}+\sum_{p=1}^{P} U_{p}+\sum_{q=1}^{Q} h_{q},
$$

где $Ф \mathrm{P}_{i}$ - финансовые ресурсы кредитно-финансовых институтов территориального образования, ориентированные на цели и задачи СЭС; $C_{n}-$ накопления населения, ориентированные на потребности в целевой сфере СЭС; $A_{k}$ - активы субъектов СЭС: финансовых структур, промышленных пред- 
приятий, проектных и других организаций; $U_{p}-$ внешние инвестиции, ориентированные на услуги СЭС; $h_{q}$ - интеллектуальный капитал сотрудников СЭС, выраженный в стоимостной форме; $i-$ индекс вида финансовых ресурсов; $n-$ индекс групп; $k$ - индекс видов активов; $p$ - индекс разновидности вложений; $q$ - индекс вида интеллектуального капитала.

На наш взгляд, следует в более широком плане рассматривать не финансовый, а именно инвестиционный потенциал, так как инвестиции имеют не только финансовую форму [7]. Требуется анализ не только финансовых, но и нефинансовых инвестиций, особенно интеллектуальной природы: ноу-хау, практического опыта участников СЭС, их компетентности, имиджа фирмы и т. д.

7. Информациионный потенцииал содержит систематизированный информационносправочный массив по всем аспектам деятельности СЭС, включая организационно-экономическую, собственно управленческую, технико-технологическую, социально-психологическую, нормативно-правовую и социальную сферы с учетом постоянных изменений в средствах вычислительной техники и программного обеспечения. Массивы информации должны проходить систематическое обновление, быть доступными для всех пользователей (с учетом определенных ограничений) и удовлетворять таким требованиям, как качество и количество информации; достоверность и точность; своевременность; полнота; полезность; сохранность и помехоустойчивость; защита от попыток несанкционированного использования и т. д. [5; 8].
8. Потребительский потенциал - это потенциал, который рождается в сфере потребления, связанной с деятельностью СЭС. Его можно охарактеризовать различной степенью динамики и разделить на две группы: демографически обусловленные (нормальные) потребности (ДОП) и деградационно-паразитические потребности (ДПП), азартные игры, табакокурение, потребление алкоголя, асоциальный образ жизни и т. д. Основная задача СЭС - удовлетворение ДОП, способствующих формированию здоровой нравственно-организованной среды $[6 ; 12]$.

9. Статусный потенц̧иал. Во многом определяет и состояние, и перспективы развития СЭС. Например, статус столичного, регионального, областного или районного образования, культурного или научного центра, международного курорта, объекта туризма, рекреации и т. д., что в значительной мере определяет направление и поиски решений СЭС.

10. Рециипрокный потенцииал. Это наименее исследованный потенциал различного рода взаимопомощи, который имеет специфическую природу, связанную с многовековыми традициями и обычаями народов России.

Таким образом, уточненная структура потенциала СЭС приобретает вид, изображенный на рисунке 1, включая все его рассмотренные выше компоненты.

До настоящего момента остается невыясненным вопрос: как и где найти возможности определения совокупного (в том числе синергетического) эффекта объединенного потенциала развития СЭС. Комплекс (совокупность) компонент образует систему, но

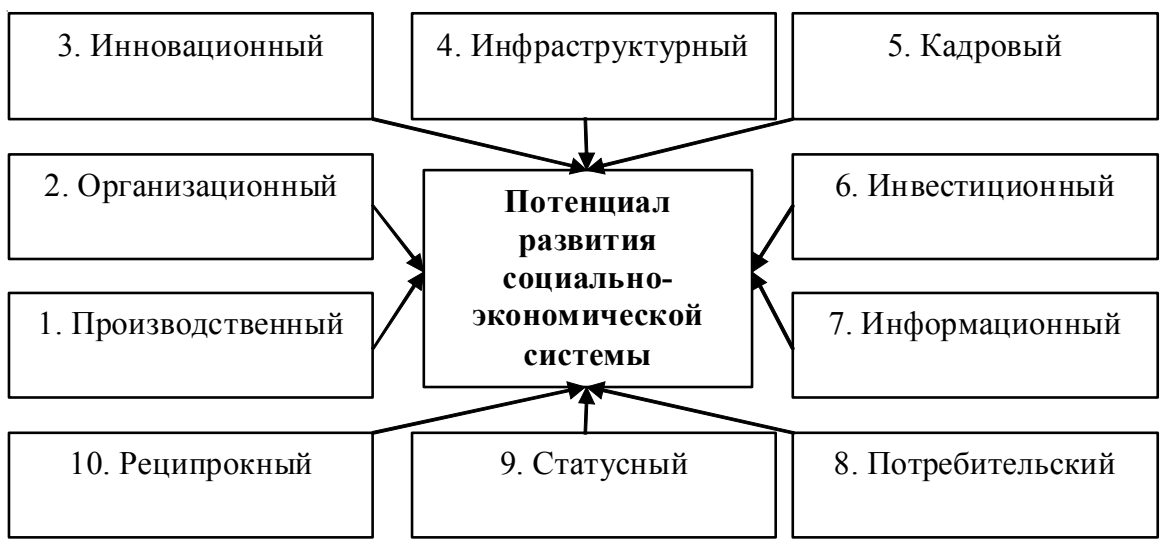

Рис. 1. Структура потенциала развития СЭС

Примечание. Составлено авторами. 


\section{ЭКОНОМИЧЕСКАЯ ТЕОРИЯ}

установить традиционными подходами степень органического единства подобных систем, обеспечивающих возникновение синергетического эффекта, весьма затруднительно (см. рис. 1).

Особенность анализа интегрированного потенциала СЭС, который обладает различными по своей природе и сущности составляющими (подсистемами), заключается в том, что он не поддается однотипным измерениям, сопоставлениям и вычислениям, поскольку каждая из компонент имеет свою физическую природу и свои единицы измерения, то есть они принципиально не аддитивны. Каждая составляющая потенциала подчиняется действию не только общих, но и своих собственных специфических законов, закономерностей и тенденций развития и имеет свою специфическую сущность. В каждой подсистеме потенциала СЭС действуют определенные принципы, цели, задачи, способы и методы решения этих задач и достижения целей. Все это обусловливает то обстоятельство, что невозможно традиционными методами составить интегративную картину целостности этого образования и возникновения синергетических эффектов в данной системе [2]. Важно, что здесь возникает как общий синергетический эффект, так и определенные частные составляющие синергетических эффектов, которые характеризуют качественную особенность взаимодействия составляющих потенциалов. Так, синергетические эффекты появляются при взаимодействии инфраструктурного, кадрового, организационного и любых других потенциалов; возникает и существенно более сложная проблема анализа и определения интегративного синергетического эффекта для самого СЭС.

Поскольку не представляется возможным выразить какими-то общими единицами неоднородные по содержанию потенциалы, можно попытаться выразить синергетический эффект в СЭС через систему связности всех потенциалов. Автор выдвигает гипотезу о том, что если существует система потенциалов, это позволяет построить матрицу связностей каждого потенциала с каждым другим потенциалом или со всеми другими одновременно. Данные предпосылки можно выразить следующим образом: например, инновационный по- тенциал, бесспорно, является функцией $F_{1}$ кадрового потенциала, то есть:

- инновационный потенциал $=F_{1}$ (кадровый потенциал);

- организационный потенциал $=F_{2}$ (финансовый потенциал);

- инвестиционный потенциал $=F_{3}$ (производственный потенциал) и т. д.

Аналогичным образом можно утверждать: потенциал $i$-й природы $=\Phi$ (потенциал 1-й природы; потенциал 2-й природы; ... потенциал $j$-й природы; ... потенциал 9-й природы).

Для того чтобы построить матрицу связности потенциалов, необходимо использовать опыт специалистов (экспертов) в области проблем управления производственными системами, имеющих достаточный уровень профессиональной компетентности, выявить и обработать их оценки в соответствии с принятыми методиками.

Исследование было ориентировано на специфику социально-экономического состояния ЧР. Результаты опроса (0 - минимальное значение связности, 100 \% - максимальное) были обработаны с учетом распределения по Стьюденту и представляют собой средние значения и ошибки среднеквадратичного отклонения $M \pm m$ (см. таблицу). Потенциалы СЭС были определены как целезадающие и целереализующие; последние выступают в качестве параметров реализации. В процессе опроса не были выявлены серьезные минимаксные отклонения мнений экспертов, требующие исключения оценок. Для удобства анализа данные представлены в процентах. Незначительные величины среднеквадратичных ошибок свидетельствуют о достаточном совпадении мнений экспертов.

Далее были определены средние значения связности каждого потенциала с каждым другим по каждой строке или столбцу.

Для того чтобы провести дальнейшее исследование возможности интерпретации использования данной матрицы, выдвигается гипотеза о том, что между максимальным значением коэффициента связности одного потенциала с другим, равным 100 \%, и минимальным, равным нулю, существует некоторое оптимальное значение уровня связности. Оно зависит от конкретного периода времени 
И.М. Бетилгириев, М.А. Бетилгириев, Х.Э. Таймасханов. Синергетический эффект экономической системы

Таблица

Матрица связности потенциалов производственных систем

\begin{tabular}{|c|c|c|c|c|c|c|c|c|c|c|c|}
\hline \multirow{2}{*}{$\begin{array}{c}\text { Потенцилы } \\
\text { целезадающие }\end{array}$} & \multicolumn{10}{|c|}{ Потенциалы целереализующие } \\
\cline { 2 - 12 } & & 2 & 3 & 4 & 5 & 6 & 7 & 8 & 9 & 10 & $\begin{array}{c}\text { Среднее } \\
\text { значение }\end{array}$ \\
\hline 1 & & $47,1 \pm$ & $45,7 \pm$ & $55,0 \pm$ & $57,1 \pm$ & $77,9 \pm$ & $30,0 \pm$ & $66,4 \pm$ & $62,9 \pm$ & $35,0 \pm$ & $53,0 \pm$ \\
& & 2,4 & 3,2 & 4,1 & 4,9 & 2,4 & 3,2 & 2,4 & 4,9 & 2,4 & 3,3 \\
\hline 2 & $47,1 \pm$ & & $67,9 \pm$ & $59,3 \pm$ & $64,3 \pm$ & $74,3 \pm$ & $55,0 \pm$ & $72,1 \pm$ & $77,9 \pm$ & $42,9 \pm$ & $62,3 \pm$ \\
& 2,4 & & 3,2 & 3,2 & 4,1 & 2,4 & 4,9 & 1,6 & 4,1 & 4,9 & 3,4 \\
\hline 3 & $45,7 \pm$ & $67,9 \pm$ & & $70,0 \pm$ & $52,1 \pm$ & $62,9 \pm$ & $60,0 \pm$ & $62,9 \pm$ & $57,1 \pm$ & $30,7 \pm$ & $56,6 \pm$ \\
& 3,2 & 3,2 & & 2,4 & 4,1 & 4,1 & 4,1 & 4,9 & 3,2 & 4,1 & 3,7 \\
\hline 4 & $55,0 \pm$ & $59,3 \pm$ & $70,0 \pm$ & & $37,1 \pm$ & $47,1 \pm$ & $51,4 \pm$ & $67,9 \pm$ & $63,6 \pm$ & $38,6 \pm$ & $54,4 \pm$ \\
& 4,1 & 3,2 & 2,4 & & 5,7 & 4,9 & 4,1 & 4,1 & 4,1 & 4,9 & 4,2 \\
\hline 5 & $57,1 \pm$ & $64,3 \pm$ & $52,1 \pm$ & $37,1 \pm$ & & $59,3 \pm$ & $57,9 \pm$ & $51,4 \pm$ & $67,1 \pm$ & $35,7 \pm$ & $53,6 \pm$ \\
& 4,9 & 4,1 & 4,1 & 5,7 & & 3,2 & 2,4 & 4,9 & 4,1 & 4,1 & 4,2 \\
\hline 6 & $77,9 \pm$ & $74,3 \pm$ & $62,9 \pm$ & $47,1 \pm$ & $59,3 \pm$ & & $51,4 \pm$ & $65,0 \pm$ & $70,0 \pm$ & $39,3 \pm$ & $60,8 \pm$ \\
& 2,4 & 2,4 & 4,1 & 4,9 & 3,2 & & 4,9 & 3,2 & 1,6 & 4,1 & 3,4 \\
\hline 7 & $30,0 \pm$ & $55,0 \pm$ & $60,0 \pm$ & $51,4 \pm$ & $57,9 \pm$ & $51,4 \pm$ & & $42,1 \pm$ & $38,6 \pm$ & $30,7 \pm$ & $46,3 \pm$ \\
& 3,2 & 4,9 & 4,1 & 4,1 & 2,4 & 4,9 & & 5,7 & 4,9 & 4,9 & 4,3 \\
\hline 8 & $66,4 \pm$ & $72,1 \pm$ & $62,9 \pm$ & $67,9 \pm$ & $51,4 \pm$ & $65,0 \pm$ & $42,1 \pm$ & & $52,1 \pm$ & $35,7 \pm$ & $57,3 \pm$ \\
& 2,4 & 1,6 & 4,9 & 4,1 & 4,9 & 3,2 & 5,7 & & 3,2 & 3,2 & 3,7 \\
\hline 9 & $62,9 \pm$ & $77,9 \pm$ & $57,1 \pm$ & $63,6 \pm$ & $67,1 \pm$ & $70,0 \pm$ & $38,6 \pm$ & $52,1 \pm$ & & $52,9 \pm$ & $60,2 \pm$ \\
& 4,9 & 4,1 & 3,2 & 4,1 & 4,1 & 1,6 & 4,9 & 3,2 & & 5,7 & 4,0 \\
\hline 10 & $35,0 \pm$ & $42,9 \pm$ & $30,7 \pm$ & $38,6 \pm$ & $35,7 \pm$ & $39,3 \pm$ & $30,7 \pm$ & $35,7 \pm$ & $52,9 \pm$ & & $37,9 \pm$ \\
& 2,4 & 4,9 & 4,1 & 4,9 & 4,1 & 4,1 & 4,9 & 3,2 & 5,7 & & 4,3 \\
\hline Среднее & $53,0 \pm$ & $62,3 \pm$ & $56,6 \pm$ & $54,4 \pm$ & $53,6 \pm$ & $60,8 \pm$ & $46,3 \pm$ & $57,3 \pm$ & $60,2 \pm$ & $37,9 \pm$ & 4,0 \\
значение & 3,3 & 3,4 & 3,7 & 4,2 & 4,2 & 3,4 & 4,3 & 3,7 & 4,3 & \\
\hline
\end{tabular}

Примечание. Составлено авторами. В таблице обозначено цифрами: 1 - инфраструктурный; 2 - инновационный; 3 - кадровый; 4 - организационный; 5 - потребительский; 6 - инвестиционный; 7 - статусный; 8 - производственный; 9 - информационный; 10 - реципрокный (взаимопомощь) потенциалы производственных систем.

и от ряда условий формирования и развития СЭС, включая уровень развития субпотенциалов (компонент), степень их взаимоадаптивности и т. д.

Логично предположить, что уровни связности одного потенциала с другим одновременно означают и появление определенных значений синергетического эффекта, порождаемого этой связностью. Таким образом, матрица полученных зависимостей связности потенциалов одновременно, в определенной степени, отражает и матрицу (поле) синергетических эффектов, являющихся функцией связности потенциалов в каждой ячейке (клетке). Есть все основания полагать, что некоторый

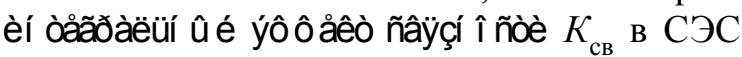
может способствовать появлению некоей многомерной функции синергетического эффекта всего потенциала СЭС. Для этого необходимы поиски оптимальных значений уровня взаимосвязей потенциалов, что представляет собой достаточно сложную и самостоятельную проблему.
Если рассматривать зависимости интегрального эффекта синергии как функцию уровня связности элементов (потенциалов), можно сделать следующие предположения. При нулевом уровне связности потенциалов, по-видимому, интегрирующий синергетический эффект $J$ в СЭС будет отрицательным, поскольку они никак не взаимодействуют друг с другом. При максимальном (равном единице) уровне связности потенциалов синергетический эффект также отрицателен, поскольку потенциалы жестко связаны друг с другом и лишены степеней свободы. При последовательном возрастании уровня связности от нулевых значений синергетический эффект возрастает, достигает максимума при некотором оптимальном значении $K_{\text {св opt }}$ и затем вновь убывает (см. рис. 2). Области $\boldsymbol{a}$ и $\boldsymbol{в}$ отражают качественные различия синергетического эффекта при дефиците или избытке уровня связности. Можно полагать, что, по крайней мере, существует хотя бы один максимум синергетического эффекта как функция связности в системе СЭС. 


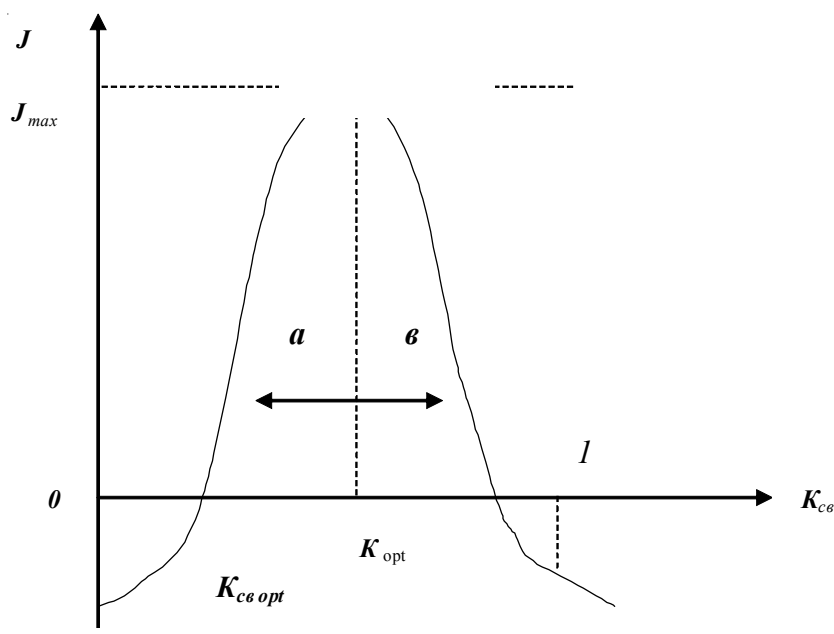

Рис. 2. Зависимость эффекта синергии от уровня связности потенциалов СЭС

Примечание. Составлено авторами.

СЭС производственной направленности являются сложными неравновесными динамическими системами, которые активно взаимодействуют с внешними потоками энергии, вещества и информации, характеризующими ресурсное обеспечение системы [16]. Внешнее взаимодействие может порождать как эффекты позитивной синергии, так и негативной. В управлении фирмой синергичность отражает сознательную, созидательную целенаправленную деятельность всего персонала СЭС, который обязан руководствоваться едиными целями и задачами коллектива как большой системы. Поискам источников и способов усиления положительной синергии и предотвращения отрицательной (негативной) синергии большинство зарубежных фирм уделяет значительное внимание, затрачивая на них 10-20 \% средств, идущих на организацию управления [20;21].

Наибольшее влияние на развитие положительной синергии в СЭС оказывают: высокий уровень общей и профессиональной культуры; профессиональные творческие связи в коллективе; знание психологии, этики, физиологии; высокий уровень морально-этических качеств персонала фирмы и грамотное использование рычагов и стимулов управления [1]. Процессы, которые порождают в обществе эффекты негативной синергии - социальная нестабильность, отсутствие четко выраженной социальной политики, деформация и деградация во многих сферах деятельности общества - обусловлены гипертрофи- рованной ролью рынка, деградацией духовных ценностей, пониженным чувством ответственности, замедленными темпами внедрения достижений НТП и т. д.

Главные задачи, которые ставятся перед обществом:

1. Усиление конструктивной, организационно-экономической целостности на уровне государства, регионов и различных субъектов хозяйствования, развитие морально-этических основ существования общества, включая всю систему отношений производства, распределения, обмена и потребления.

2. Повышение уровня профессионализма, моральной ответственности кадров. Фундаментальным фактором формирования позитивной социальной синергии следует считать конструктивное развитие сотрудничества между государством и рыночными структурами.

Необходимо отметить, что свойства синергии изучены крайне недостаточно в теории и практике управления, они нередко трактуются явно механистически. Примеров этому можно привести достаточно на каждом из уровней управления. Так, по некоторой логике, каждый из вновь создаваемых органов управления должен усиливать эффект синергии и повышать экономический эффект. Однако, к сожалению, хорошо известно, что бессистемное образование новых комитетов, комиссий, департаментов или министерств (или, напротив, их исключение) ухудшает эффективность экономики, создает дополнительные элементы нестабильности. Добавление плохо обоснованных и недостаточно 
структурированных элементов в системах управления неизбежно ухудшает эффект синергии, понижает эффективность и устойчивость организационных систем и даже приводит их к деградации или разрушению. По-видимому, в организационно-экономических системах могут быть весьма полезными некоторые структуры-«антагонисты», которые, хотя и несколько уменьшают эффект целевой функции экономических систем, однако в значительно большей степени повышают их устойчивость и стабильность темпов развития. Это могут быть, например, органы правопорядка, охраны окружающей среды, здравоохранения и другие.

Таким образом, анализ СЭС производственной направленности как динамической, многопараметрической, вероятностной, открытой, самоорганизующейся и саморегулируемой системы требует развития теоретических поисков усиления ее интегративных и адаптивных свойств. Поскольку все составляющие системы имеют различную качественную основу и обладают неаддитивными свойствами, целесообразно исследовать СЭС как интегрированное образование на основе анализа связности составляющих его подсистем (потенциалов). Указанная связность, определяемая на основе экспертных оценок, образует матрицу, в которой каждый ее элемент отражает возможный частичный синергетический эффект, а вся матрица в целом характеризует возникающий в СЭС интегральный синергетический эффект, имеющий некоторое оптимальное значение. Рост позитивных синергетических эффектов непосредственно связан с созидательной профессиональной деятельностью персонала СЭС.

\section{СПИСОК ЛИТЕРАТУРЫ}

1. Абылгазиев, И. И. Процессы глобализации и проблема нового мироустройства / И. И. Абылгазиев, И. В. Ильин // Век глобализации. - 2009. № 2. - С. 40-60.

2. Авдонина, С. Г. Синергетический эффект кластерных образований и параметры его оценки / С. Г. Авдонина // Региональная экономика и управление : электрон. науч. журн. - 2012. - № 1 (29).

3. Асаул, В. В. Научные основы инновационного развития территории на примере создания особых экономических зон / В. В. Асаул. - СПб. : Наука, 2006. -217 c.
4. Белошапкин, А. А. Организация системы управления ассоциациями промышленных предприятий в целях инновационного развития / А. А. Белошапкин // Экономическое возрождение России. 2012. - № 4 (34). - C. 99-104.

5. Гейтс, Б. Бизнес со скоростью мысли / Б. Гейтс. - Изд. 2-е, испр. - М. : ЭКСМО-Пресс, 2001. -480 c.

6. Ефимов, В. А. Воспроизводство трудового потенциала агропромышленного комплекса : дис. ... д-ра экон. наук : 08.00.05 / Ефимов Виктор Алексеевич. - СПб. : Изд-во СПбГИЭУ, 2008. -293 с.

7. Катасонов, В. Ю. Инвестиционный потенциал экономики: механизмы формирования и использования / В. Ю. Катасонов. - М. : Анкил, 2005. $-328 \mathrm{c}$.

8. Когут, А. Е. Информационные основы социально-экономического мониторинга / А. Е. Когут, В. Е. Рохчин. - СПб. : Изд-во ИСЭП PAH, 1995. $-143 \mathrm{c}$.

9. Кузнецов, Б. Л. Введение в экономическую синергетику / Б. Л. Кузнецов. - Набережные Челны : Изд-во КамПИ, 1999. - 326 с.

10. Кузнецов, Б. Л. Экономическая синергетика как методология экономического развития / Б. Л. Кузнецов // Экономическое возрождение России. - 2004. - № 2. - С. 34-36.

11. Кэмпбелл, Э. Стратегический синергизм / Э. Кэмпбелл, Ласч Саммерс. - 2-е изд. - СПб. : Питер, 2004. - 416 c.

12. Лукьяненко, В. И. Homo consumens - человек потребляющий / В. И. Лукьяненко, М. В. Хабаров, А. В. Лукьяненко // Век глобализации. 2009. - № 2. - С. 149-159.

13. Очерки экономической науки. Актуальные проблемы / под общ. ред. Н. Ю. Яськовой. - М. : КЦ МАГМУ, 2005. - Ч. 1. - 274 c.

14. Пешков, В. В. Методологические основы управления экономическим потенциалом развития инвестиционно-строительной сферы : дис. ... д-ра экон. наук : 08.00.05 / Пешков Виталий Владимирович. - М., 2006. -315 c.

15. Пуряев, А. С. Синергетическая эффективность проекта / А. С. Пуряев // Экономическое возрождение России. - 2005. - № 1 (3). - С. 44-49.

16. Садыков, Х. С. Комплексное ресурсное обеспечение - основа реализации инвестиционностроительных программ Чеченской Республики / Х. С. Садыков // Вестник Инжекона. СПбГИЭУ.2011. - № 1 (44). - C. 81-90.

17. Садыков, Х. С. Механизм управления социально-экономическим развитием Чеченской Республики на основе эффективного использования инновационного потенциала / Х. С. Садыков, Л. А. Мусаев // Вестник гражданских инженеров. 2012. - № 3 (32). - C. 351-358. 
18. Садыков, Х. С. Организационно-методические и методологические проблемы формирования синергетического потенциала инвестиционно-строительного комплекса Чеченской Республики / Х. С. Садыков // Вестник гражданских инженеров. -2013 . - № 4 (39). - С. 206-213.

19. Садыков, Х. С. Программно-целевое обеспечение кадрового потенциала инвестиционностроительного комплекса Чеченской Республики / Х. С. Садыков // Научно-технические ведомости СПбГТУ. - СПб., 2011. - № 1 (114). - С. 151-158.

20. Cluster policy in Europe. A brief summary of cluster policies in 31 European countries. Oxford Research AS. 2008. - Electronic text data. - Mode of access: http://clusterobservatorv.eu/system/modules/ com.gridnine.opencms.modules.eso/providers/getpdf. jsp?uid=100146, free (date of access: 22.11.2012). - Title from screen.

21. Ketels, C. H. M. The Development of the Cluster Concept-Present Experiences and Further Developments. Pater prepared for NRW conference on plusters, Duisburg, Germany, 5 Dec. 2003 / C. H. M. Ketels. -HarvardBusiness School, 2003. - Electronic text data. - Mode of access: http://www.isc.hbc.edu/pdf/ Frontiers_of_Cluster Research_2003.11.23.pdf(date of access: $12 . \overline{03} .2013)$. Title from screen.

\section{REFERENCES}

1. Abylgaziev I.I., Ilyin I.V. Protsessy globalizatsii i problema novogo miroustroystva [The Processes of Globalization and the Problem of a New World Order]. Vek globalizatsii, 2009, no. 2, pp. 40-60.

2. Avdonina S.G. Sinergeticheskiy effekt klasternykh obrazovaniy i parametry ego otsenki [Synergetic Effect of Cluster Formations and Parameters of Its Evaluation]. Regionalnaya ekonomika i upravlenie: elektron. nauch. zhurn., 2012, no. 1 (29).

3. Asaul V.V. Nauchnye osnovy innovatsionnogo razvitiya territorii na primere sozdaniya osobykh ekonomicheskikh zon [Scientific Foundations of Innovative Development of the Territory on the Example of Creating Special Economic Zones]. Saint Petersburg, Nauka Publ., 2006. 217 p.

4. Beloshapkin A.A. Organizatsiya sistemy upravleniya assotsiatsiyami promyshlennykh predpriyatiy $\mathrm{v}$ tselyakh innovatsionnogo razvitiya [Organization of the System for Managing Associations of Industrial Enterprises for the Purposes of Innovative Development]. Ekonomicheskoe vozrozhdenie Rossii, 2012, no. 4 (34), pp. 99-104.

5. Gates B. Biznes so skorostyu mysli [Thought-Speed Business]. Moscow, EKSMO-Press, 2001. 480 p.
6. Efimov V.A. Vosproizvodstvo trudovogo potentsiala agropromyshlennogo kompleksa: dis.... d-ra ekon. nauk [Reproduction of the Labour Potential of the Agro-Industrial Complex. Dr. econ. sci. diss.]. Saint Petersburg, Izd-vo SPbGIEU, 2008. 293 p.

7. Katasonov V.Yu. Investitsionnyy potentsial ekonomiki: mekhanizmy formirovaniya $i$ ispolzovaniya [Investment Potential of the Economy: Mechanisms of Formation and Use]. Moscow, Ankil Publ., 2005. 328 p.

8. Kogut A.E., RokhchinV.E. Informatsionnye osnovy sotsialno-ekonomicheskogo monitoringa [Information Bases of Socio-Economic Monitoring]. Saint Petersburg, Izd-vo ISEP RAN, 1995. 143 p.

9. Kuznetsov B.L. Vvedenie v ehkonomicheskuyu sinergetiku [Introduction to Economic Synergetics]. Nab. Chelny, KPI Publ., 1999. $326 \mathrm{p}$.

10. Kuznetsov B.L. Ekonomicheskaya sinergetika kak metodologiya ekonomicheskogo razvitiya [Economic Synergetics as a Methodology of Economic Development]. Ekonomicheskoe vozrozhdenie Rossii, 2004, no. 2, pp. 34-36.

11. Campbell E., Summers L. Strategicheskiy sinergizm [Strategic Synergism]. Saint Petersburg, Piter Publ., 2004. 416 p.

12. Lukyanenko V.I., Khabarov M.V., Lukyanenko A.V. Homo consumens - chelovek potreblyayushchiy [Homo Consumens - a Consuming Person]. Vek globalizatsii, 2009, no. 2, pp. 149-159.

13. Yaskova N.Yu. Ocherki ekonomicheskoy nauki. Aktualnye problemy [Essays of Economic Science. Relevant Problems]. Moscow, KTs MAGMU, 2005, part 1.274 p.

14. Peshkov V.V. Metodologicheskie osnovy upravleniya ekonomicheskim potentsialom razvitiya investitsionno-stroitelnoy sfery: dis. ... d-ra ekon. nauk [Methodological Fundamentals of Managing the Economic Potential of Investment and Construction Sphere. Dr. econ. sci. diss.]. Moscow, 2006. 315 p.

15. Puryaev A.S. Sinergeticheskaya effektivnost proekta [Synergetic Efficiency of the Project]. Ekonomicheskoe vozrozhdenie Rossii, 2005, no. 1 (3), pp. 44-49.

16. Sadykov Kh.S. Kompleksnoe resursnoe obespechenie - osnova realizatsii investitsionnostroitelnykh programm Chechenskoy Respubliki [Complex Resource Support is the Basis for the Implementation of Investment and Construction Programs of the Chechen Republic]. Vestnik Inzhekona. SPbGIEHU, 2011, no. 1 (44), pp. 81-90.

17. Sadykov Kh.S., Musaev L.A. Mekhanizm upravleniya sotsialno-ekonomicheskim razvitiem Chechenskoy Respubliki na osnove effektivnogo ispolzovaniya innovatsionnogo potentsiala [The Mechanism of Managing the Social and Economic 
Development of the Chechen Republic on the Basis of the Effective Use of Innovative Potential]. Vestnik grazhdanskikh inzhenerov, 2012, no. 3 (32), pp. 351-358.

18. Sadykov Kh.S. Organizatsionnometodicheskie i metodologicheskie problemy formirovaniya sinergeticheskogo potentsiala investitsionno-stroitelnogo kompleksa Chechenskoy Respubliki [Organizational and Methodological Problems of Synergetic Potential Formation of the Investment and Construction Complex of the Chechen Republic]. Vestnik grazhdanskikh inzhenerov, 2013, no. 4 (39), pp. 206-213.

19. Sadykov Kh.S. Programmno-tselevoe obespechenie kadrovogo potentsiala investitsionnostroitelnogo kompleksa Chechenskoy Respubliki
[Program and Targeted Provision of Personnel Potential of the Investment and Construction Complex of the Chechen Republic]. Nauchno-tekhnicheskie vedomosti SPbGTU, 2011, no. 1 (114), pp. 151-158.

20. Cluster policy in Europe. 31 European countries. Oxford Research AS. 2008. URL: http:// clusterobservatorv.eu/system/modules/com. gridnine.opencms.Modules.eso/providers/ getpdf. jsp?Uid=100146. (accessed November 22, 2012).

21. Ketels S.H.M. The Development of the Cluster Concept - Present Experiences and Further Developments. Pater prepared for the $N R W$ conference on plusters, Duisburg, Germany, 5 Dec. 2003. Harvard Business School, 2003. URL: http:// www.isc.hbc.edu/pdf/ Frontiers_of_Cluster Research_2003.11.23.pdf. (accessed March 12, 2013).

\section{Information About the Authors}

Isa M. Betilgiriev, Postgraduate Student, Grozny State Oil Technical University named after M.D. Millionshchikov, Prosp. Kh. Isaeva, 100, 364061 Grozny, Chechen Republic, Russian Federation, betilgiriev@gmail.com.

Maula A. Betilgiriev, Doctor of Sciences (Economics), Professor, Grozny State Oil Technical University named after M.D. Millionshchikov, Prosp. Kh. Isaeva, 100, 364061 Grozny, Chechen Republic, Russian Federation, betilgiriev@mail.ru.

Khasan E. Taymaskhanov, Doctor of Sciences (Economics), Professor, Rector, Honored Economist of the Russian Federation, Grozny State Oil Technical University named after M.D. Millionshchikov, Prosp. Kh. Isaeva, 100, 364061 Grozny, Chechen Republic, Russian Federation, rector@gstou.ru.

\section{Информация об авторах}

Иса Маулаевич Бетилгириев, аспирант, Грозненский государственный нефтяной технический университет им. академика М.Д. Миллионщикова, просп. Х. Исаева, 100, 364061 г. Грозный, Чеченская Республика, Российская Федерация, betilgiriev@gmail.com.

Маула Абдурахманович Бетилгириев, доктор экономических наук, профессор, Грозненский государственный нефтяной технический университет им. академика М.Д. Миллионщикова, просп. Х. Исаева, 100, 364061 г. Грозный, Чеченская Республика, Российская Федерация, betilgiriev@mail.ru.

Хасан Элимсултанович Таймасханов, доктор экономических наук, профессор, ректор, заслуженный экономист Российской Федерации, Грозненский государственный нефтяной технический университет им. академика М.Д. Миллионщикова, просп. Х. Исаева, 100, 364061 г. Грозный, Чеченская Республика, Российская Федерация, rector@gstou.ru. 